\title{
The relationship between masticatory muscles activity and tinnitus - preliminary study
}

\author{
GRZEGORZ ZIELIŃSKI ${ }^{1, A-E}$, MARTA SUWAŁA ${ }^{1, A, B, D-F}$, MICHA $Ł$ GINSZT ${ }^{1, c-E}$, \\ ORCID ID: 0000-0002-2849-0641 \\ JACEK SZKUTNIK 2, D, F, PIOTR GAWDA ${ }^{1, \mathrm{~B}, \mathrm{~F}}$ \\ ORCID ID: 0000-0002-7842-1775 'ORCID ID: 0000-0003-0265-9960 \\ ORCID ID: 0000-0002-0800-6103 \\ ${ }^{1}$ Chair and Department of Rehabilitation, Physiotherapy and Balneotherapy, Medical University of Lublin, Poland \\ ${ }^{2}$ Department of Functional Masticatory Disorders, Medical University of Lublin, Poland
}

A - Study Design, B - Data Collection, C - Statistical Analysis, D - Data Interpretation, E - Manuscript Preparation, F - Literature Search, G - Funds Collection

Summary Background. Structures of temporomandibular joints and ear have a common phylogenetic origin. Muscular imbalance in the area of masticatory muscles may lead to tinnitus.

Objectives. A comparison of muscular tension and masticatory muscles asymmetry between women with tinnitus and without tinnitus.

Material and methods. From a group of 96 examined responders, we found 32 women (aged $22 \pm 2$ years) who exhibited no temporomandibular joint disorders and who had not been treated otolaryngologically. The examined women were then placed within two groups: with tinnitus (16 people) and without tinnitus (16 people). Next, we examined the muscular activity in the temporomandibular muscles by way of sEMG at rest, when the teeth were clenched and when the mouth is opened maximally. To assess muscular asymmetry, the asymmetry index was used.

Results. Despite the lower bioelectrical muscular tension of masticatory muscles at rest and during the examined functions in people with tinnitus, the results were not important statistically $(p>0.05)$. However, we observed crucial statistical differences in masseter muscle asymmetry in people with tinnitus when clenching teeth $(p=0.042)$, and in the number of people with muscle asymmetry in the area of the masticatory muscles at rest $(p=0.012)$ and when teeth are clenched $(p=0.013)$, in comparison to a healthy group. Conclusions. There is a relationship between changes in the asymmetry index of the masticatory muscles and the occurrence of tinnitus. In order to confirm the results, we recommend further examination in this area and longer observation time.

Key words: tinnitus, temporomandibular joint disorder, masseter muscle, temporal muscle, electromyography.

Zieliński G, Suwała M, Ginszt M, Szkutnik J, Gawda P. The relationship between masticatory muscles activity and tinnitus - preliminary study. Fam Med Prim Care Rev 2019; 21(1): 66-69, doi: https://doi.org/10.5114/fmpcr.2019.82981.

\section{Background}

Tinnitus (otalgia) is the perception of the sensation of the sound without any acoustical external factors. This problem may affect 10 to $17 \%$ of the entire population [1] and about 1 in 10 adults. Duration of exposure to noise in the workplace and at leisure is correlated with the frequency of tinnitus and are its probable risk factors [2]. Many people get used to the phantom sound, but tinnitus seriously worsens the quality of life of about $1-2 \%$ of all people [3]. Tinnitus may be experienced as squeaks, whistles, chirps, bubbling sounds, pulsations, howls, paper rustling, or sea humming [4]. Evidence from animal models and the examination of people with tinnitus indicate that while damage of cochlea is a trigger, the majority of tinnitus cases are not generated by irritant processes persisting in the cochlea, but by changes that occur in the central auditory tracts. Research on the molecular mechanisms that underlie neuronal changes in tinnitus are at a very early stage and constitute a limit for research [5].

It is worth noting that tinnitus does not have to be associated with otogenic factors. The constant perception of sounds can lead to deterioration of mental state, stress and depressive disorders in 6 to $25 \%$ of all people affected by this disorder [6]. Tinnitus may be caused or modulated by the stimulation of omatosensory, somatomotor, and visual-motor systems [1, 7].

In tinnitus, the role of hyperactive muscle tissues stimulated through trigger points has been noted [8-10]. Strong spasms of the temporomandibular joint (TMJ), head and neck and extremities, vertical or horizontal eye movements and activated trigger points may temporarily modulate the psychoacoustic features of tinnitus $[11,12]$. Neuroplasticity seems to play a central role in this modulation capability, suggesting that aberrant interactions between sensory modalities, sensory-motor systems and neurocognitive and neuromuscular networks may contribute to the development of somatosensory tinnitus [11]. In patients with temporomandibular joint disease, a constant improvement in tinnitus symptoms was observed after the targeted therapy of temporomandibular disorders. Somatosensory tinnitus is often overlooked by otolaryngologists and is not fully investigated during the diagnostic process [11].

Temporomandibular joint disorder is a dental disease that can also be considered a population disease because of its chronic and widespread prevalence. Increasing otolaryngological symptoms such as sudden loss of hearing or loss of hearing, the feeling of ear blockage and pain in the ear, pain and burning in the throat, difficulties in swallowing, tinnitus and dizziness are more and more often observed with this disorder. This confirms earlier information about somatosensory tinnitus Undoubtedly, it constitute a diagnostic and therapeutic difficulty [12]. Therefore, the study of the relationship between masticatory muscle activity and laryngological disorders may be important in terms of diagnosis and treatment of tinnitus. 


\section{Objectives}

The aim of the presented study is to compare muscular tension and masticatory muscles asymmetry between women with and without tinnitus.

\section{Material and methods}

\section{Participants}

A group of 96 people volunteered to be examined. They were first generally assessed medically and then dentally in accordance with the Polish version of a dual-axis system for the diagnosis of temporomandibular disorders (RDC/TMD) [13]. From the above-mentioned group, we recruited 32 healthy women (aged $22 \pm 2$ years) without temporomandibular disorders (TMD) or neurological, otolaryngological, and mental disorders, while 64 people were excluded from the study. Based on RDC/TMD protocol [13], the study group was divided into two parts: without tinnitus (16 people) and with tinnitus (16 people).

\section{Measurement}

The examination of temporal muscle (TA) and masseter muscle (MA) bioelectrical tension was made utilizing an 8-channel surface electromyography apparatus BioEMG, supported by a BioPak Measurement system. The activity of masticatory muscles (TA, MM) was evaluated at rest, when the teeth were clenched (by biting upon a cotton dental roll) for three contractions lasting two seconds and during maximum opening of the mouth 3 times per two seconds. The methodology of sEMG examination was in accordance with Wieczorek et al. [14]. To assess asymmetry in the TA and MM muscles, the asymmetry index from the model of Naeije et al. was included [14, 15].

Based on the results, the asymmetry index (AsI) was calculated using the formula below, wherein RMS means root means square:

$$
A s I=\left(R M S_{\text {right }}-R M S_{\text {left }}\right) /\left(R M S_{\text {right }}+R M S_{\text {left }}\right) \times 100 .
$$

Herein, the value of the index varies between +100 and -100 . A positive value stands for a greater input from the muscles on the right side, whereas a negative value will indicate a greater input from the muscles on the left side. The results which equal 0 indicate muscle equity between the right and left side [15].

\section{Statistical methods}

The IBM SPSS STATISTICS 21 program was used to prepare the statistical analysis. To analyse the SEMG results in the three conditions (during rest, clenched and maximum opening) and the index of asymmetry, ANOVA testing was applied.

\section{Permissions and ethics}

This study was approved by the ethical committee of Medical University of Lublin, Poland (KE-0254/73/2017) and was in accordance with the Declaration of Helsinki for Human Research. All participants were informed about the procedures they would undergo and gave their consent to participate in the tests.

\section{Results}

The masticatory muscles (temporal and masseter) mean bioelectrical activity $(\mu \mathrm{V})$ was found to be always higher in the healthy group than in the tinnitus group (at rest, while clenched and at maximum opening). However, these results were not statistically significant.

TA and MM muscles mean bioelectrical activity $(\mu \mathrm{V})$ in the tinnitus group was lower than that in the healthy group (at rest, while clenched and at maximum mouth opening), however, the results were only statistically significant $(p<0.05)$ within the temporal muscle while the teeth were clenched (Tab. 2).

The mean value of the masticatory muscle asymmetry index (temporal and masseter at rest, while clenched and at maximal mouth opening, indicates the extent of muscle activity. In the tinnitus group, while at rest, there was more activity on the opposite side. These results, however, were not important statistically $(p>0.05)$ (Tab. 3).

The mean value of temporal muscle (TA) and masseter muscle (MM) asymmetry indicates the extent of muscle activity. In the tinnitus group, we saw variable temporal muscle activity while at rest and while clenching, the muscles were more active on the left side, but during maximal opening, they were more active on the right side. Important statistical differences were observed in the size of the asymmetry index between left and right side masseter muscles $(p<0.05)$ (Tab. 4).

Within the masticatory muscles, asymmetry while at rest was observed in 12 people in the tinnitus group and in 5 people in the healthy group $(n=16)$. In the function of clenching, in the tinnitus group there were 7 people with asymmetry and in the healthy group - one person. The results were important statistically $(p<0.05)$. Asymmetry during maximal mouth opening was observed in 5 people with tinnitus and in 6 people in the healthy group. The results were not important statistically $(p>0.05)$ (Tab. 5).

\begin{tabular}{|c|c|c|c|c|c|c|c|}
\hline Group & $n$ & $\begin{array}{l}\text { Mean masticatory muscles } \\
\text { activity (TA, MM): at rest } \\
(\mu \mathrm{V})\end{array}$ & $p$ & $\begin{array}{l}\text { Mean masticatory muscles } \\
(\mathrm{TA}, \mathrm{MM}) \text { tension: teeth } \\
\text { clenched }(\mu \mathrm{V})\end{array}$ & $p$ & $\begin{array}{l}\text { Mean masticatory muscles } \\
(\mathrm{TA}, \mathrm{MM}) \text { : maximal opening } \\
(\mu \mathrm{V})\end{array}$ & $p$ \\
\hline \begin{tabular}{|l} 
With \\
tinnitus
\end{tabular} & 16 & 2.276 & 0.410 & 101.688 & 0.158 & 7.156 & 0.465 \\
\hline $\begin{array}{l}\text { Without } \\
\text { tinnitus }\end{array}$ & 16 & 2.828 & 0.410 & 126.463 & 0.158 & 9 & 0.465 \\
\hline
\end{tabular}

\begin{tabular}{|c|c|c|c|c|c|c|c|}
\hline Muscle & $n$ & $\begin{array}{l}\text { Mean sEMG activity: } \\
\text { at rest }(\mu \mathrm{V})\end{array}$ & $p$ & $\begin{array}{l}\text { Mean sEMG activity: } \\
\text { teeth clenched }(\mu \mathrm{V})\end{array}$ & $p$ & $\begin{array}{l}\text { Mean sEMG activity: } \\
\text { maximal opening }(\mu \mathrm{V})\end{array}$ & $\bar{p}$ \\
\hline TA (1) & 16 & 2.649 & \multirow[t]{2}{*}{0.742} & 99.059 & \multirow[t]{2}{*}{$0.040 *$} & 6.228 & \multirow[t]{2}{*}{0.494} \\
\hline TA (2) & 16 & 2.828 & & 139.566 & & 7.225 & \\
\hline MM (1) & 16 & 1.903 & \multirow[t]{2}{*}{0.381} & 104.316 & \multirow[t]{2}{*}{0.620} & 8.084 & \multirow[t]{2}{*}{0.516} \\
\hline $\mathrm{MM}(2)$ & 16 & 2.829 & & 113.359 & & 10.775 & \\
\hline
\end{tabular}

*the result important statistically. 


\begin{tabular}{|c|c|c|c|c|c|c|c|}
\hline Group & $n$ & $\begin{array}{l}\text { Mean values of asymme- } \\
\text { try index of masticatory } \\
\text { muscles (TA, MM): at rest }\end{array}$ & $p$ & $\begin{array}{l}\text { Mean values of asymme- } \\
\text { try index of masticatory } \\
\text { muscles (TA, MM): teeth } \\
\text { clenched }\end{array}$ & $p$ & $\begin{array}{l}\text { Mean values of asym- } \\
\text { metry index of mastica- } \\
\text { tory muscles (TA, MM): } \\
\text { maximal opening }\end{array}$ & $p$ \\
\hline \begin{tabular}{|l} 
With \\
tinnitus
\end{tabular} & 16 & -5.516 & \multirow[t]{2}{*}{0.103} & +3.903 & \multirow[t]{2}{*}{0.682} & +5.977 & \multirow[t]{2}{*}{0.907} \\
\hline $\begin{array}{l}\text { Without } \\
\text { tinnitus }\end{array}$ & 16 & +3.649 & & +2.087 & & +5.436 & \\
\hline
\end{tabular}

\begin{tabular}{|c|c|c|c|c|c|c|c|}
\hline Muscle & $n$ & $\begin{array}{l}\text { Mean values of asymmetry } \\
\text { index: at rest }\end{array}$ & $p$ & $\begin{array}{l}\text { Mean values of asymmetry } \\
\text { index: teeth clenched }\end{array}$ & $p$ & $\begin{array}{l}\text { Mean values of asym- } \\
\text { metry index: at maximal } \\
\text { opening }\end{array}$ & $p$ \\
\hline TA (1) & 16 & -14.009 & \multirow[t]{2}{*}{0.063} & -4.714 & \multirow[t]{2}{*}{0.257} & +4.308 & \multirow[t]{2}{*}{0.761} \\
\hline TA (2) & 16 & +4.006 & & +1.938 & & +2.077 & \\
\hline MM (1) & 16 & +2.977 & \multirow[t]{2}{*}{0.956} & +12.52 & \multirow[t]{2}{*}{$0.042^{*}$} & +7.647 & \multirow[t]{2}{*}{0.826} \\
\hline MM (2) & 16 & +3.292 & & +2.237 & & +8.795 & \\
\hline
\end{tabular}

*the result important statistically.

Table 5. A comparison of the number of people with masticatory muscle (TA, MM) asymmetry in the tinnitus group and in the healthy group at rest, when clenched and at maximum mouth opening

\begin{tabular}{|c|c|c|c|c|c|c|c|}
\hline Group & $n$ & $\begin{array}{l}\text { Number of people with } \\
\text { masticatory muscle asym- } \\
\text { metry during rest }\end{array}$ & $p$ & $\begin{array}{l}\text { Number of people with } \\
\text { masticatory muscle } \\
\text { asymmetry while teeth } \\
\text { clenched }\end{array}$ & $p$ & $\begin{array}{l}\text { Number of people with } \\
\text { masticatory muscle asym- } \\
\text { metry while at maximal } \\
\text { opening }\end{array}$ & $p$ \\
\hline $\begin{array}{l}\text { With } \\
\text { tinnitus }\end{array}$ & 16 & 12 & \multirow[t]{2}{*}{$0.012 *$} & 7 & \multirow[t]{2}{*}{$0.013^{*}$} & 5 & \multirow[t]{2}{*}{0.721} \\
\hline $\begin{array}{l}\text { Without } \\
\text { tinnitus }\end{array}$ & 16 & 5 & & 1 & & 6 & \\
\hline
\end{tabular}

*the result important statistically.

\section{Discussion}

Changes in masticatory muscles asymmetry and activity are dysfunctions in the biomechanical masticatory muscular system that can cause dysfunctions in neighbouring systems. In our examination, crucial statistical differences were observed in the asymmetry of the masticatory muscles (TA, MM): at rest and when the teeth were clenched. Such abnormal head area muscular activity and stimulation has an effect upon the omatosensory, somatomotor and visual-motor systems, and can lead to and modulate tinnitus [1]. Our results are consistent with Teachey et al. [8] who put forward that tinnitus results from such muscular dysfunction. The observed lower average bioelectrical muscular tension may be caused by latent trigger points [16], and can be complacent with the affection of tinnitus trigger points $[9,10]$.

According to Majewska-Szaniec et al., hearing ailments without symptoms of hearing loss and with healthy good dental situation suggest the existence of a relationship between these ailments with disorders in the temporomandibular joints [17]. Buergers et al. point out that the frequency of tinnitus is 8 times higher in participants with TMD than in participants without TMD [19], while Ralli et al. noted that in patients with temporomandibular joint disease and tinnitus, a constant improvement in tinnitus symptoms was observed after targeted therapy of temporomandibular disorders [11]. Attansio et al. add that when the most common causes of tinnitus, such as otological disorders and neurological diseases, are excluded, the functionality of the temporo-mandibular joint can be accessed and ultimately any pathology treated for improvement in tinnitus, and even its termination [18].
In our study, such factors were excluded because the mentioned groups were examined for any potential TMD. However, a change in the activity of the masticatory muscles that does not cause pain may have affected the occurrence of tinnitus. The people in our studies had altered muscle activity without pain, so they were not classified as having a temporomandibular disorder. However, change in masticatory muscles activity that persists for a long time may lead to the development of dysfunctions in the stomatognathic system.

According to research done by Mapelli et al., patients with TMD had less muscle symmetry [20]. The above studies are consistent with the work of De Felício et al. according to which patients with TMD showed greater asymmetry between right and left muscle pair, and more unbalanced contraction activity of contralateral masseter and temporal muscles [21]. The results of research conducted by Mapella et al. and De Felício et al. are contradictory to our research. The subjects in the present study did not have symptoms of TMD, but in the tinnitus group, significantly more frequent muscular asymmetry was demonstrated. This implies that, as observed in our research, a change in activity that does not cause pain in the muscle of mastication can also be associated with tinnitus. This may be the first signal of TMD formation, however, further research is needed on the subject of tinnitus and their correlation with muscle asymmetry and TMD as there is a lack of publications on the change of muscle of mastication activity as indicated by SEMG. Were such a connection confirmed, however, that observation may help in the acceleration of clinical diagnostics and tinnitus tratment. 


\section{Limitations of the study}

The above work has several limitations. The study group is quite small $(n=32)$. In addition, the electromyographic study included only two muscle groups (temporal, masseter). Moreover, future study should ascertain whether normalization of tension within the face would reduce the intensity of tinnitus. Still our research will provide the opportunity to establish a causal relationship between the masticatory muscle activity and tinnitus. Were this confirmed, it can significantly improve the diagnostic possibilities and programming of therapy in people with tinnitus associated with the activity of the masticatory muscles.

\section{Conclusions}

There is a relationship between changes in the asymmetry index of the masticatory muscles and the occurrence of tinnitus. In order to confirm the results, we recommend further examination in this area and longer observation time.

Source of funding: This work was funded from the authors' own resources.

Conflicts of interest: The authors declare no conflicts of interest.

\section{References}

1. Sanchez TG, Rocha CB. Diagnosis and management of somatosensory tinnitus: review article. Clinics 2011; 66(6): 1089-1094.

2. Bhatt JM, Lin HW, Bhattacharyya N. Tinnitus epidemiology: prevalence, severity, exposures and treatment patterns in the United States. JAMA Otolaryngol - Head Neck Surg 2016; 142(10): 959-965.

3. Langguth B, Kreuzer PM, Kleinjung T, et al. Tinnitus: causes and clinical management. Lancet Neurol 2013; 12(9): 920-930.

4. Ferendiuk E, Zajdel K, Pihut M. Incidence of otolaryngological symptoms in patients with temporomandibular joint dysfunctions. BioMed Res Int 2014. Available from URL: https://www.ncbi.nlm.nih.gov/pmc/articles/PMC4094732/.

5. Eggermont JJ, Roberts LE. Tinnitus: animal models and findings in humans. Cell Tissue Res 2015; 361(1): 311-336.

6. Joos K, Vanneste S, De Ridder D. Disentangling depression and distress networks in the tinnitus brain. PLoS ONE 2012; 7(7). Available from URL: https://www.ncbi.nlm.nih.gov/pmc/articles/PMC3395649/.

7. Sanchez TG, Kii MA. Modulating Tinnitus with visual, muscular, and tactile stimulation. Semin Hear 2008; 29(4): 350-360.

8. Teachey WS, Wijtmans EH, Cardarelli F, et al. Levine RA. Tinnitus of myofascial origin. Int Tinnitus J 2012; 17(1): 70-73.

9. Bezerra Rocha CAC, Sanchez TG, Tesseroli de Siqueira JT. Myofascial trigger point: a possible way of modulating tinnitus. Audiol Neurootol 2008; 13(3): 153-160.

10. Rocha CB, Sanchez TG. Efficacy of myofascial trigger point deactivation for tinnitus control. Braz J Otorhinolaryngol $2012 ; 78(6)$ : 21-26.

11. Ralli M, Greco A, Turchetta R, et al. Somatosensory tinnitus: current evidence and future perspectives. J Int Med Res 2017; 45(3): 933-947.

12. Won JY, Yoo S, Lee SK, et al. Prevalence and factors associated with neck and jaw muscle modulation of tinnitus. Audiol Neurootol 2013; 18(4): 261-273.

13. Osiewicz MA, Lobbezoo F, Loster BW, et al. Research Diagnostic Criteria for Temporomandibular Disorders (RDC/TMD): The Polish version of a dual-axis system for the diagnosis of TMD.* RDC/TMD form. J Stoma 2013; 66: 576-649.

14. Wieczorek A, Loster J, Loster BW, et al. Correlation between activity and asymmetry indices and skeletal classes in symptomatic-free young adults. J Stoma 2013; 66(6): 780-760.

15. Naeije M, McCarroll RS, Weijs WA. Electromyographic activity of the human masticatory muscles during submaximal clenching in the inter-cuspal position. J Oral Rehabil 1989; 16(1): 63-70.

16. Richter P, Hebgen E. Punkty spustowe i łańcuchy mięśniowo-powięziowe w osteopatii i terapii manualnej. Łódź: Wydawnictwo Galaktyka; 2010 (in Polish).

17. Maciejewska-Szaniec Z, Maciejewska B, Wiskirska-Woźnica B, et al. Szumy uszne u chorych z zaburzeniami czynnościowymi układu ruchowego narządu żucia. Fam Med Prim Care Rev 2013; 15(3): 347-348 (in Polish).

18. Attanasio $G$, Leonardi A, Arangio $P$, et al. Tinnitus in patients with temporo-mandibular joint disorder: proposal for a new treatment protocol. J Craniomaxillofac Surg 2015; 43(5): 724-727.

19. Buergers R, Kleinjung $\mathrm{T}$, Behr M, et al. Is there a link between tinnitus and temporomandibular disorders? J Prosthet Dent 2014; 111(3): 222-227.

20. Mapelli A, Zanandréa Machado BC, Giglio LD, et al. Reorganization of muscle activity in patients with chronic temporomandibular disorders. Arch Oral Biol 2016; 72: 164-171.

21. De Felício CM, Ferreira CLP, Medeiros APM, et al. Electromyographic indices, orofacial myofunctional status and temporomandibular disorders severity: a correlation study. J Electromyogr Kinesiol 2012; 22(2): 266-272.

Tables: 5

Figures: 0

References: 21

Received: 18.07.2018

Reviewed: 3.08 .2018

Accepted: 29.08 .2018

Address for correspondence:

Marta Suwała, MSc

Zakład Rehabilitacji i Fizjoterapii UM

ul. Magnoliowa 2

20-143 Lublin

Polska

Tel.: +48 81 448-67-83

E-mail: marta.suwala@umlub.pl 